\title{
The Impact of E-Management Innovation System on Improving Corporate Operating Performance
}

\author{
Li-Wei Lin \\ The School of International Business, Zhejiang Yuexiu University, No.428 Kuaiji Road, Yue \\ Cheng District, Shaoxing 312000, China
}

Shih-Yung Wei

Business School of Yulin Normal University,China(Corresponding Author)

Received: August 1, $2021 \quad$ Accepted: August 23, $2021 \quad$ Published: August 24, 2021

doi:10.5296/bms.v12i2.18959ＵRL: https://doi.org/10.5296/bms.v12i2.18959

\begin{abstract}
E-management innovation system in recent years, the supply chain management system has been continuously upgrading and innovating, the main purpose is to improve the efficiency of its supply chain and reduce costs. This study investigates the effect of e-management system on supply chain efficiency. We use three assumptions to design, information technology innovation, information environment, relationship risk to do in-depth discussion on whether the efficiency of the supply chain will be affected. In this study, the Likert seven-point scale was used to design the survey method. In this study, $\mathrm{N}=331$ questionnaires were issued, and 195 questionnaires were finally available, which met the minimum sample number. The main object of this study is to investigate the senior executives in zhejiang electronics industry. This result proves that e-management innovation system can improve the efficiency of its supply chain. We observed and verified the correlation results through three dependent variables and one fruit variable.
\end{abstract}

Keywords: Information technology, information environment, relationship risk, investigation method

\section{Introduction}

In recent years, many scholars have put forward the view of supply chain efficiency, which will lead to zhejiang electronics industry companies can increase their competitive advantage. The main purpose of this study is to investigate the three hypotheses and verify whether the 
correlation between the hypotheses can be established. E-management is the common response chain management structure that enterprises need to promote under the current global competition, in order to achieve the overall enterprise supply chain efficiency. The main goal of our research is to improve the internal and external information sharing ability of enterprises, and we observe whether the e-construction can achieve the degree of information sharing between its supply chain, so as to improve the performance of its supply chain. Lee (1997) mentioned that organizations can achieve their organizational 3A goals (agility, adaptability, adjustability) through information sharing and partnerships. Enterprise information security communication is mainly based on the establishment of a secure environment for the exchange of information between the two parties, and information sharing can affect the performance of the entire supply chain through the entire information environment.

Ellarm \& Hendrick (1995) put forward that in the process of cross-organizational information sharing, supply chain organizations need to highly share each other's technical information, and then obtain the trust relationship between the two parties. The main purpose of this research is to improve the performance and efficiency of the whole supply chain through the innovation of e-technology. Through e-technology innovation, we help organizations to achieve greater efficiency and effectiveness in the entire supply chain operation process. In recent years, many enterprises are also developing and investing in robotic arms, hoping to increase the overall industrial efficiency through the further improvement of e-transformation, so as to improve and upgrade the performance of the entire organization in operation. This technological innovation enables the organization to improve performance and reduce costs to achieve its organizational goals. Craighead et al. (2006) Internet technology can facilitate the implementation of assistance in key elements of the supply chain. Gunasekaran and Ngai (2004) have a goal that the key factor through cooperation and information sharing between supply chain members needs to be built on a long-term relationship. We observed that previous literature data, such as RFID, Wi-Fi, and GPS, can help the cooperation between members of the entire supply chain at any time or anywhere, in such a way that technological innovation can affect the performance of the entire supply chain. These innovative technologies enable real-time observation of the entire system, allowing the entire supply chain system to reduce its risk and agility to respond to the situation. Such a set of technology innovation system can improve the whole operation mode, break the traditional business model, and achieve real-time information sharing between manufacturers and buyers.

We aimed at these similar subjects of science and technology innovation system mainly for the electronics industry of zhejiang province, because of the electronics industry belongs to labor-intensive industries empirically, each manufacturing process needs to be close to combine, so many of today's companies will continue to import the new E technology to integrate manufacturing, to hope to be able to continue to improve the whole supply chain efficiency and the performance of the company. Faced with the continuous increase of labor costs, many enterprises will strengthen e-technology improvement to reduce their operating costs. Zhu et al. (2006) mentioned that mobile supply chain management is important for 
manufacturing companies to realize, including buyer and seller business procedures. Different innovative technologies can improve the performance of the entire organization, which is why we include the factors of technological innovation into the discussion and investigation in this research. With the increasingly fierce competition among enterprises in Zhejiang electronics industry, many executives of enterprises are considering how to reduce costs and improve the efficiency of supply chain in the whole operation process. This is also why we include the environment of information sharing degree into the discussion in this study. On the other hand, we examine the whole business process to see if the buying and selling relationship between the two parties creates a risk relationship between them. This risk relationship across business process management partners can have a significant impact on the organization. The main objective concept of management between partners is to manage mutual dependencies through mechanisms to achieve the goals and tasks of both parties. Such consideration of relationship risk factors will lead to the establishment of the overall risk relationship system.

Faems, Janssens, Madhok, \& Looy (2008) Protect and coordinate the entire operational system relationship alliance by focusing on the existing relationship program architecture, mechanism and strong emphasis on trust. We are interested in this concept of partner governance, and we introduce and observe the impact of overall partner management on supply chain performance through the concept of formal mechanisms. We found in the collection of holistic models in strategic partner risk management that there is a need to look at managerial risk, relational risk, and acceptable risk in the organization, to control the formal mechanism and relational mechanism in this series of processes, and ultimately to produce overall organizational performance. The most important thing in this process is to establish the overall partnership by establishing the operational mechanism of both parties.

\section{Theory and Development Assumptions}

It is mainly to establish whether there is a logical relationship between the dependent variable and the fruit variable. I hope to use the mutual logical relationship between the three hypotheses to do the case study and research of the electronics industry in Zhejiang. In this study, whether the dependent variable information innovation, information environment and relationship risk will have a correlation with the fruit variable supply chain performance is investigated.

This study explores the theoretical development of dependent variables and fruit variables through Figure 1. Supply chain management was put forward in the early 1980s (Oliver and Webber,1982). Improve supply chain management performance through various innovative technologies. Two goals can be achieved through effective and good supply face management :(1) to improve the performance of a single organization and (2) to improve the performance of the systemic supply chain. The measurement of organizational performance can be analyzed and measured from the perspective of internal and external members of the organization. Such organizational measurement can lead to improved performance across the supply chain. The most important goal of supply chain performance is to achieve the 
partnership between buyer and seller, so that both parties can ensure and trust the cooperation between the two parties, so as to achieve the improvement of both parties' performance in the supply chain. For example, the customer can know the seller's production status in real time, or when the delivery can be on time? Or can you know the quality of the product in real time? Through such cooperation mode, the overall supply chain performance target is achieved and improved.

There is a lot of literature in the supply chain that discusses the impact of the information environment on the performance of the entire supply chain. Some scholars compare the manufacturing information environment of nearby Asian countries (e.g., Mainland China, Vietnam, Indonesia, Malaysia, etc.). Chong et al.(2009) proposed that In order to improve their competitiveness, Malaysian manufacturing companies have implemented the improvement of their technology to improve supply chain management, which is still a challenge to the Manufacturing environment in Malaysia. We look at the use of technological innovations in the supply chain in different countries to understand whether the adoption, development and application of management practices by manufacturing companies throughout the supply chain management process will have a relevant impact on the overall supply chain performance during the diffusion of the information environment. Through the design and establishment of information environment factors, the most important thing is to establish a good information environment sharing and data exchange, so as to achieve the improvement of the entire supply chain performance. In today's increasingly competitive manufacturing environment, buyer and seller partnerships can be achieved through the implementation of innovative technology. We mentioned earlier that in the era of globalization, in order to remain competitive, enterprises need to apply strategic supply chain to maintain their efficiency and reduce operating costs (for example, through the application and upgrading of software). In recent years, many studies firmly believe that the application of network technology will cause its impact on manufacturing supply chain management. The main point of this study is to combine technology and environmental theory to do a combination and discussion. Chou et al. (2004) mentioned that past studies focused on the impact of adoption of EDI and B2B business technologies on business performance. Through previous literature reading, we can understand that early technology can affect the entire organization's supply chain performance.

In terms of relational risk variables, we mainly want to reduce risk and integrate the system view of the whole operation mechanism through the operation process. In previous studies, scholars have mentioned many successful partner assumptions, indicating that enterprises are skilled in using its mechanism and controlling its behavioral surface. The development of the organization and the risk are related, the organization in the development and measurement strategy needs to have a set of standards to control its risk. In the whole supply chain management operation, the concept is also the same. Buyers and sellers should control the risks of their cooperation relationship and control and prevent them in advance. Chapman(2008) mentioned that risk avoidance, risk transfer or financing need to be prevented through the insurance mechanism. We look primarily through relationship risk to 


\section{Macrothink}

see that in different situations, external business risks go on to supersede the relationship. How an enterprise understands a partnership risk relationship depends on a number of factors. These risks will also affect the final supply chain performance relationship.

The research model is as follows:

H1: Whether technological innovation is relevant to supply chain performance

$\mathrm{H} 2$ : Is the information environment relevant to supply chain performance

H3: Whether relationship risk is relevant to supply chain performance

The design is illustrated by the following hypothetical architecture Fig.1:

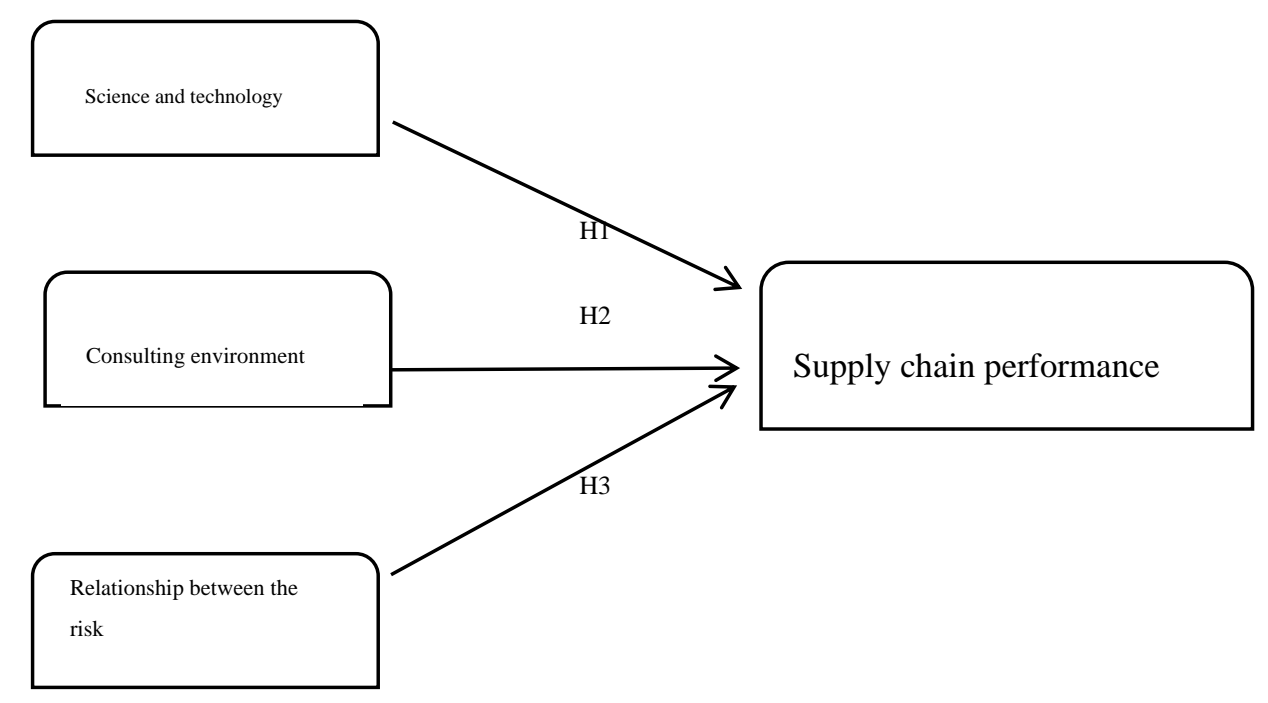

Figure 1. Assuming that architecture

\section{Study Design and Data Collection}

Correlation analysis is to detect the closeness of the relationship between variables and observe the correlation coefficient. However, regression analysis focuses on the quantitative change law among variables, and performs certain mathematical equations to describe the relationship between variables, so as to determine the influence degree of the change of one or more variables on another specific variable.

The purpose of correlation analysis is to describe the linear relationship between two continuous variables, while regression analysis is based on the linear relationship between two variables to further analyze the predictive relationship between the two variables. A significant correlation coefficient can only indicate a certain degree of correlation between the two variables, but the causal and sequential relationship between the two variables cannot be ascertained.

Computing is the correlation coefficient of variation situation of two variables, belong to the symmetrical design, expressed as a $\mathrm{X} \leftrightarrow \mathrm{Y}$, and return to 'aim is to use a variable to predict 


\section{Macrothink}

the change of another variable, $\mathrm{X}, \mathrm{Y}$, two variables have their role, in the calculation of regression coefficient, $\mathrm{X}, \mathrm{Y}$ variable for asymmetric design, expressed in $\mathrm{X}$ and $\mathrm{Y}$ or $\mathrm{X}$ and $\mathrm{Y}$.

In part IV, 5 factors (fator 1-5) can be generated from the previous factor analysis, but the reliability of fator5 is not over 0.6 , so it is not included in the analysis and discussion. The following are the selected factors:

$$
\begin{aligned}
& \mathbf{F} 1=\mathrm{B} 8 * 0.311+\mathrm{B} 12 * 0.269+\mathrm{B} 22 * 0.203+\mathrm{B} 24 * 0.244+\mathrm{B} 26 * 0.171+\mathrm{B} 28 * 0.244 \\
& \mathbf{F} 2=\mathrm{A} 8 * 0.293+\mathrm{A} 10 * 0.277+\mathrm{B} 2 * 0.282+\mathrm{B} 4 * 0.293+\mathrm{B} 6 * 0.293 \\
& \mathbf{F 3}=\mathrm{B} 14 * 0.465+\mathrm{B} 16 * 0.348+\mathrm{B} 18 * 0.361 \\
& \mathbf{F} 4=\mathrm{B} 10 * 0.606+\mathrm{B} 20 * 0.4962
\end{aligned}
$$

The DV part is from B1, B3, B5..., B27 and B29 were analyzed for factors, and all the four groups of factors generated passed reliability and validity tests. Therefore, one group of factors was selected to play the role, and the factor scores were as follows:

$$
\text { D1 }=0.40696 * \mathrm{~B} 7+0.30369 * \mathrm{~B} 9+0.40123 * \mathrm{~B} 11 ;
$$

Since the $\mathrm{P}$ value of overall Model is less than 0.05 , this factor is suitable to be used as the regressive DV.

\section{Sample number test}

Since there are $4 \mathrm{IVs}$, the minimum number of samples should be $4 * 12=48$. The total amount of data in this study is 331 , and after deducting the data reserved for cross validity, the valid data ratio is 195 , which meets the requirement of minimum number of samples.

\begin{tabular}{l|l}
\hline Number of observations read & 200 \\
\hline Number of observations used & 195 \\
\hline Number of observations with missing values & 5 \\
\hline
\end{tabular}

\section{Assumption testing}

Due to the observation of the Shapir-Wilk values of the six factors, only the $\mathrm{P}$ value of D2 $>0.05$ is normal, and the P values of the rest F1 $\sim$ F5 are all $<0.05$, which is not normal distribution. Therefore, the central limit theorem must be adopted to converge the data. The values are as follows: 
D1

Analysis of variance

\begin{tabular}{l|l|l|l|l|l}
\hline source & DF & Sum of squares & The mean square & F Value & $\operatorname{Pr}>$ F \\
\hline model & 1 & 138.05800 & 138.05800 & 180.01 & $<.0001$ \\
\hline error & 193 & 148.01955 & 0.76694 & & \\
\hline The corrected total & 194 & 286.07755 & & & \\
\hline
\end{tabular}

F1

Normality test

\begin{tabular}{l|l|l|l|l}
\hline \multicolumn{2}{|l|}{} & \multicolumn{2}{l}{ statistics } & \multicolumn{2}{l}{ P Value } \\
\hline Shapiro-Wilk & W & 0.946344 & $\operatorname{Pr}<\mathrm{W}$ & $<0.0001 \mathrm{I}$ \\
\hline Kolmogorov-Smirnov & $\mathrm{D}$ & 0.092221 & $\operatorname{Pr}>\mathrm{D}$ & $<0.0100$ \\
\hline Cramer-von Mises & W-Sq & 0.309531 & $\operatorname{Pr}>\mathrm{W}-\mathrm{Sq}$ & $<0.0050$ \\
\hline Anderson-Darling & A-Sq & 2.224206 & $\operatorname{Pr}>\mathrm{A}-\mathrm{Sq}$ & $<0.0050$ \\
\hline
\end{tabular}

F2

Normality test

\begin{tabular}{l|l|l|l|l}
\hline test & \multicolumn{2}{|l|}{ statistics } & P Value \\
\hline Shapiro-Wilk & W & 0.74718 & $\operatorname{Pr}<\mathrm{W}$ & $<0.0001$ \\
\hline Kolmogorov-Smirnov & D & 0.206109 & $\operatorname{Pr}>\mathrm{D}$ & $<0.0100$ \\
\hline Cramer-von Mises & W-Sq & 1.712955 & $\operatorname{Pr}>$ W-Sq & $<0.0050$ \\
\hline Anderson-Darling & A-Sq & 10.74248 & $\operatorname{Pr}>$ A-Sq & $<0.0050$ \\
\hline
\end{tabular}


F3

Normality test

\begin{tabular}{l|l|l|l|l}
\hline test & \multicolumn{2}{|l|}{ statistics } & \multicolumn{2}{l}{ P Value } \\
\hline Shapiro-Wilk & W & 0.8164 & $\operatorname{Pr}<\mathrm{W}$ & $<0.0001$ \\
\hline Kolmogorov-Smirnov & D & 0.209115 & $\operatorname{Pr}>\mathrm{D}$ & $<0.0100$ \\
\hline Cramer-von Mises & W-Sq & 1.887553 & Pr $>$ W-Sq & $<0.0050$ \\
\hline Anderson-Darling & A-Sq & 11.13089 & Pr $>$ A-Sq & $<0.0050$ \\
\hline
\end{tabular}

F4

Normality test

\begin{tabular}{l|l|l|l|l}
\hline \multicolumn{2}{|l|}{} & \multicolumn{2}{l}{ statistics } & \multicolumn{2}{l}{ P Value } \\
\hline Shapiro-Wilk & W & 0.949523 & $\operatorname{Pr}<\mathrm{W}$ & $<0.0001$ \\
\hline Kolmogorov-Smirnov & $\mathrm{D}$ & 0.117693 & $\mathrm{Pr}>\mathrm{D}$ & $<0.0100$ \\
\hline Cramer-von Mises & W-Sq & 0.345623 & $\mathrm{Pr}>\mathrm{W}-\mathrm{Sq}$ & $<0.0050$ \\
\hline Anderson-Darling & A-Sq & 2.340014 & $\operatorname{Pr}>\mathrm{A}-\mathrm{Sq}$ & $<0.0050$ \\
\hline
\end{tabular}

The $\mathrm{P}$ value of $\mathrm{F} 1, \mathrm{~F} 2$ and $\mathrm{F} 4$ is $<0.05$, and the $\mathrm{P}$ value of $\mathrm{F} 3$ is $>0.05$, so the regression equation is:

$$
\text { D1 }=\mathrm{f} 1 * 0.31487+\mathrm{f} 2 * 0.27357+\mathrm{f} 4 * 0.36445
$$


Parameter estimates

\begin{tabular}{|c|c|c|c|c|c|c|c|c|c|c|}
\hline \multirow[t]{2}{*}{ Variable } & \multirow[t]{2}{*}{ DF } & \multirow[t]{2}{*}{$\begin{array}{l}\text { Parameter } \\
\text { estimates }\end{array}$} & \multirow[t]{2}{*}{$\begin{array}{l}\text { Standard } \\
\text { error }\end{array}$} & \multirow[t]{2}{*}{$\begin{array}{l}\mathrm{T} \\
\text { Value }\end{array}$} & \multirow[t]{2}{*}{$\begin{array}{l}\operatorname{Pr}> \\
\mathrm{t} \mid\end{array}$} & \multirow{2}{*}{$\begin{array}{l}\begin{array}{l}\text { Analysis } \\
\text { variance }\end{array} \\
\begin{array}{l}\text { Standard } \\
\text { error }\end{array}\end{array}$} & of & unequal & \multirow[t]{2}{*}{$\begin{array}{l}\text { Margin } \\
\text { error }\end{array}$} & \multirow[t]{2}{*}{$\begin{array}{l}\text { Variation } \\
\text { expansion }\end{array}$} \\
\hline & & & & & & & $\begin{array}{l}\mathrm{T} \\
\text { Value }\end{array}$ & $\begin{array}{l}\operatorname{Pr}>\mid \\
\mathrm{t}\end{array}$ & & \\
\hline Intercept & 1 & -0.78656 & 0.39401 & -2.00 & 0.0473 & 0.39229 & -2.01 & 0.0464 & & 0 \\
\hline $\mathrm{F} 1$ & 1 & 0.31487 & 0.04590 & 6.86 & $<.0001$ & 0.04381 & 7.19 & $<0.001$ & 0.57241 & 1.74700 \\
\hline $\mathrm{F} 2$ & 1 & 0.27357 & 0.04060 & 6.74 & $<.0001$ & 0.04400 & 6.22 & $<.0001$ & 0.72438 & 1.38049 \\
\hline F3 & 1 & -0.10461 & 0.05515 & -1.90 & 0.0594 & 0.04728 & -2.21 & 0.0281 & 0.68168 & 1.46696 \\
\hline F4 & 1 & 0.36445 & 0.03886 & 9.38 & $<0.001$ & 0.03938 & 9.25 & $<0.001$ & 0.71734 & 1.39404 \\
\hline
\end{tabular}

As $\mathrm{P}>0.05$ is linear and homogeneous

Identification of first and second differential specifications

\begin{tabular}{l|l|l}
\hline DF & chi-square & Pr>chi-sq \\
\hline 14 & 19.05 & 0.1632 \\
\hline
\end{tabular}

\section{3.test of multi-Collinearity}

Since the tolerances of F1, F2 and F4 are all greater than 0.1 , collinearity is not a problem.

\begin{tabular}{|c|c|c|c|c|c|c|c|c|c|c|}
\hline \multicolumn{11}{|c|}{ Parameter estimates } \\
\hline \multirow[t]{2}{*}{ Variable } & \multirow[t]{2}{*}{$\mathrm{DF}$} & \multirow[t]{2}{*}{$\begin{array}{l}\text { Parameter } \\
\text { estimates }\end{array}$} & \multirow[t]{2}{*}{$\begin{array}{l}\text { Standard } \\
\text { error }\end{array}$} & \multirow[t]{2}{*}{$\begin{array}{l}\mathrm{T} \\
\text { Value }\end{array}$} & \multirow[t]{2}{*}{$\begin{array}{l}\operatorname{Pr}>1 \\
\mathrm{t} \mid\end{array}$} & \multirow{2}{*}{$\begin{array}{l}\begin{array}{l}\text { Analysis } \\
\text { variance }\end{array} \\
\begin{array}{l}\text { Standard } \\
\text { error }\end{array}\end{array}$} & \multirow{2}{*}{\begin{tabular}{l}
\multicolumn{1}{c}{ of } \\
$\mathrm{T}$ \\
Value
\end{tabular}} & \multirow{2}{*}{$\begin{array}{l}\text { unequal } \\
\operatorname{Pr}>\mid \\
\mathrm{t} \mid\end{array}$} & \multirow[t]{2}{*}{$\begin{array}{l}\text { Margin } \\
\text { error }\end{array}$} & \multirow[t]{2}{*}{$\begin{array}{l}\text { Variation } \\
\text { expansion }\end{array}$} \\
\hline & & & & & & & & & & \\
\hline Intercept & 1 & -0.78656 & 0.39401 & -2.00 & 0.0473 & 0.39229 & -2.01 & 0.0464 & & 0 \\
\hline $\mathrm{F} 1$ & 1 & 0.31487 & 0.04590 & 6.86 & $<.0001$ & 0.04381 & 7.19 & $<0.001$ & 0.57241 & .74700 \\
\hline $\mathrm{F} 2$ & 1 & 0.27357 & 0.04060 & 6.74 & $<.0001$ & 0.04400 & 6.22 & $<.0001$ & 0.72438 & 3.8049 \\
\hline F3 & 1 & -0.10461 & 0.05515 & -1.90 & 0.0594 & 0.04728 & -221 & 0.0281 & 0.68168 & .46696 \\
\hline $\mathrm{F} 4$ & 1 & 0.36445 & 0.03886 & 9.38 & $<0.001$ & 0.03938 & 9.25 & $<.0001$ & 0.71734 & .39404 \\
\hline
\end{tabular}

4.Outlier

Deviation value refers to the value of $\mathrm{R}$ Student value greater than 2 and less than -2 . A total of 11 data were found. The original data and collated data are as follows: 




\begin{tabular}{ll}
\hline Obs & RStudent \\
\hline 8 & -2.2421 \\
\hline 11 & 2.1326 \\
\hline 75 & -2.0726 \\
\hline 100 & -2.2433 \\
\hline 138 & -2.0202 \\
\hline 145 & -3.0936 \\
\hline
\end{tabular}

\section{Influential observation}

Because there are 3 IV left, the Cov ratio should be bound between 1-3(3/195) 1+3(3/195) $=0.9538 \sim 1.0462$, and the two values with the most deviation (100 and 145) should be deleted from the data.

\section{Prediction Efficiency}

After re-executing the regression analysis, F1, F2 and F4 remained unchanged in IV, but R2 increased from 0.7032 to 0.7142 . The regression equation changed as follows:

Before the deletion, $\mathbf{D} 1=\mathrm{f} 1 * 0.31487+\mathrm{f} 2 * 0.27357+\mathrm{F} 4 * 0.36445$

After the deletion, $\mathrm{D} 1=\mathrm{f} 1 * 0.31266+\mathrm{f} 2 * 0.27163+\mathrm{F} 4 * 0.35521$ 


\begin{tabular}{l|l|l|l}
\hline Root MSE & 0.66845 & R squared & 0.7032 \\
\hline Double mean & 5.53893 & Adjust R squared & 0.6970 \\
\hline Coefficient of variation & 12.06812 & & \\
\hline
\end{tabular}

\begin{tabular}{l|l|l|l}
\hline Root MSE & 0.64679 & R squared & 0.7142 \\
\hline Double mean & 5.56278 & Adjust R squared & 0.7081 \\
\hline Coefficient of variation & 11.62708 & & \\
\hline
\end{tabular}

\section{Prediction Accuracy}

Cross validity means that the original data is divided into two groups, and then the data analysis results of the two groups are compared to see if there is any significant difference. The total data ratio is 331, and the estimate data and Holdout data are 193 and 131, respectively, after deducting invalid data. The results showed that R2 was 0.7142 and 0.78656 respectively, and there was no significant difference.

\begin{tabular}{l|l|l|l}
\hline Root MSE & 0.64679 & R squared & 0.7142 \\
\hline Double mean & 5.56278 & Adjust R squared & 0.7081 \\
\hline Coefficient of variation & 11.62708 & & \\
\hline
\end{tabular}

Pearson correlation coefficient. $\mathrm{N}=131$, Prob $>|\mathrm{r}|$ (under H0) : Rho=0

\begin{tabular}{c|c|c}
\hline \multirow{2}{*}{$\mathrm{P} 1$} & $\mathrm{P} 1$ & $\mathrm{D} 1$ \\
\hline \multirow{2}{*}{$\mathrm{D} 1$} & 1.00000 & 0.78656 \\
\cline { 2 - 3 } & & $<.0001$ \\
\hline & 0.78656 & 1.00000 \\
\hline
\end{tabular}

\section{Discuss and Apply Practice}

E-technology innovation, information environment and relationship risk will affect the performance of supply chain. The greatest contribution of this study is to explore these 
relationships through e-diffusion theory, information sharing theory and relationship risk theory, so as to achieve the final supply chain performance. In this study, based on the literature studied by previous scholars, we expanded and extended the whole statistical software analysis by using SAS software. The number of samples was 331, available data recovery was 195 , and the recovery rate was $59 \%$. Through the whole statistical analysis with SAS software, we can learn that these three hypotheses have passed the reliability and validity test, which can directly verify that the scientific and technological innovation, information environment and relationship risk will directly and positively affect the performance of the supply chain. Our empirical process allows decision makers to understand the factors that future manufacturing companies can take into account to ensure the success of supply chain performance. (e.g., trust, partnership, information sharing on relationship risk). Many scholars have studied that information sharing requires trust between two parties, including that the contract of the whole mechanism also requires trust mechanism. The greatest contribution and application of this study is to establish partnership cooperation through trust mechanism and reduce its transaction risk.

\section{Conclusions and Future Research}

This research conducts a survey through the mainland electronics industry in Zhejiang, but there are still some limitations that cannot be achieved to the best:

(I) Restrictions on questionnaire distribution:

This questionnaire was distributed through friends in Zhejiang, through friends or electronic industry executives, but in the process of distributing the questionnaire, I do not know whether the middle and senior executives fill in the questionnaire, and the rigor will have a qualitative impact. In addition, we originally intended to send out the online questionnaire and the actual questionnaire. Considering the financial problems, if the follow-up researchers want to combine the two questionnaires in the future, they need to pay attention to the test of non-response bias. Because the data on the network is uncertain, and need to pay attention to the security of the database.

(II) Limitations of research variables:

This study is mainly aimed at the electronics industry in Zhejiang, with the local Zhejiang mainland enterprises as the questionnaire object. I have not included other foreign-funded enterprises. In the process of writing, I mentioned the coming of globalization, and I should include the ideas of western enterprises' environmental factors, so as to compare the differences between eastern and Western ideas. We are mainly considering eastern companies this time. This is where the design of the study falls short. The suggestion of this study for subsequent researchers is that western firms can be expanded as the survey subjects and innovative ideas of Western firms can be redesigned as variables. In this investigation, we can only look and analyze from the perspective of China's scientific and technological revolution. In the future, we should add a western perspective to the overall design to make a balanced action. I believe that innovative knowledge and ideas will be generated for future research. 


\section{References}

Chapman, R. J. (2008). Simple tools and techniques for enterprises risk management. Chichester: John Wiley \& Sons, Ltd.

Chong, A. Y. L., Ooi, K. B., Lin, B. S., \& Tang, S. Y. (2009). Influence of interorganizational relationships on SMEs' e-business adoption. Internet Research, 19(3), 313-331. https://doi.org/10.1108/10662240910965379

Chou, D. C., Tan, X., \& Yen, D. C. (2004). Web technology and supply chain management. Information Management and Computer Security, 12(4), 338-349. https://doi.org/10.1108/09685220410553550

Craighead, C., Patterson, J. W., Roth, P. L., \& Segars, A. H. (2006). Enabling the benefits of supply chain management systems: An empirical study of electronic data interchange (EDI) in manufacturing. International Journal of Production Research, 44(1), 135-157. https://doi.org/10.1080/00207540500161019

Ellram, L. M., \& Hendrick, T. E. (1995). Partnering Characteristics: A Dyadic Perspective. Journal of Business Logistics, 16:41-63.

Faems, D., Janssens, M., Madhok, A., \& Looy, B. (2008). Towards an integrative perspective on alliance governance: Connecting contract design, trust dynamics and contract application. The Academy of Management Journal, 51, 1053-1078. https://doi.org/10.5465/amj.2008.35732527

Gunasekaran, A., \& Nagi, E. (2004). Information systems in supply chain intergration and management. European Journal of Operational Research, 159(2), 269-295. https://doi.org/10.1016/j.ejor.2003.08.016

Lee, H. L., Padmanabhan, V., \& Wang, S. (1997). The Bullwhip Effect in Supply Chains. Sloan Management Review, 38(2), 93-102.

Oliver, K. R., \& Webber, M. D. (1982). "Supply -Chain Management: Logistics Catches Up with Strategy" Outlook, 1982, cit.

Zhu, K., Kraemer, K. L., \& Xu, S. (2006). The process of innovation assimilation by firms in different countries: a technology diffusion perspective on e-business. Management Science, 52(10), 1557. https://doi.org/10.1287/mnsc.1050.0487

\section{Copyright}

Copyright for this article is retained by the author(s), with first publication rights granted to the journal.

This is an open-access article distributed under the terms and conditions of the Creative Commons Attribution license (http://creativecommons.org/licenses/by/4.0/). 